Revista de
Economìd
Contemporâned

\title{
PADRÃO DE CONSUMO E PRESSÃO AMBIENTAL NO BRASIL
}

\author{
Lucio Flávio da Silva Freitas ${ }^{a}$

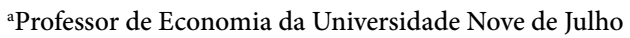 \\ Artigo recebido em 24/04/2013 e aprovado em 12/08/2014.
}

RESUMO: Este artigo examina as conexões entre o consumo das famílias e a pressão ambiental no Brasil. O objetivo é investigar como o aumento do consumo das famílias brasileiras nas últimas duas décadas modificou a pressão ambiental do sistema econômico. A avaliação é feita a partir da decomposição estrutural de um modelo de insumo produto associado aos dados das Pesquisas de Orçamentos Familiares. Exclusive os efeitos da Mudança de Uso da Terra e Florestas, o nível de emissão continua subindo com o aumento da produção e do consumo. $\mathrm{O}$ efeito composição diminuiu as emissões do consumo, quase exclusivamente devido ao setor agropecuário. O efeito tecnológico também reduziu o conteúdo de gases do efeito estufa (GEE) por unidade do PIB, entretanto, estas reduções foram superadas pelo efeito escala do consumo.

PALAVRAS-CHAVE: Análise de decomposição estrutural; emissões de GEE; insumo-produto; padrão de consumo.

CLASSSIFICAÇÃO JEL: Q51; Q56; R20; C67.

Correspondência para Lucio Flávio da Silva Freitas.

E-mail: lucioffreitas@yahoo.com.br. 


\title{
CONSUMPTION PATTERN AND ENVIRONMENTAL PRESSURE IN BRAZIL
}

\begin{abstract}
This paper examines the connections between household consumption and environmental pressure in Brazil. The aim is to investigate how increased consumption of Brazilian families in the last two decades has changed the environmental pressure of the economic system. The method chosen was the structural decomposition analysis associated with the Household Budget Surveys. Environmental pressure increased during the period considered. Excluding the effects of Land Use Change and Forestry, the emission level keeps rising with the increased production and consumption. The composition effect decreased emissions of consumption, mostly due to the agricultural sector; this reduction was overcome by the scale effect.
\end{abstract}

KEYWORDS: Structural decomposition analysis; GEE emissions; input-output; consumption pattern. 


\section{INTRODUÇÃO}

A preocupação com os limites ambientais do crescimento econômico remontam ao final da década de 1960, com a publicação do relatório Limits of growth (Meadows et al., 1968). Desde então, a atenção dedicada ao tema cresceu significativamente. Hoje a evidência científica corrobora a hipótese de que a intervenção antrópica sobre os ecossistemas está próxima de alcançar fronteiras que tornariam irreversíveis transformações severas do meio ambiente (Rockström et al., 2009; Jackson, 2009).

Aos países em desenvolvimento cabe buscar uma trajetória de crescimento que atenda às necessidades materiais da sua população e ao mesmo tempo minimize sua pressão ambiental. Se afinal toda produção tem por finalidade o consumo, conhecer as mudanças na cesta de bens adquirida pelas famílias pode indicar oportunidades e desafios para a sustentabilidade dos ecossistemas.

No ano de 2009, o consumo agregado das famílias brasileiras somou R 1.940 bilhões, o que representou 60\% do Produto Interno Bruto (PIB). Em comparação com o ano de 1990 o consumo das famílias mais do que dobrou. O índice de Gini para a desigualdade de renda domiciliar diminuiu de 0,614 para 0,543 (PNAD/IBGE, 2012). Quase 60 milhões de brasileiros ascenderam à chamada classe $\mathrm{C}$, cuja faixa de rendimento varia entre R\$1.200,00 e R \$ 5.174,00, na definição de Neri (2012).

Evidentemente, o atual ciclo de desenvolvimento da economia brasileira tem repercussões sobre o ecossistema. Assim, a pergunta que orienta este trabalho é: o aumento do consumo das famílias brasileiras nas últimas duas décadas modificou a pressão ambiental do sistema econômico? Ou foi compensado pelo aumento da produtividade e avanço tecnológico?

Seria razoável supor que o aumento da renda dos mais pobres tenha sido convertido principalmente em aquisições para a satisfação das necessidades primárias, por conseguinte, em consumo de bens e serviços mais intensivos em materiais, que exigem maior transformação de recursos naturais e de energia. Por sua vez, o consumo de combustíveis fósseis está mais associado aos níveis mais altos de renda (POF/IBGE, 2013).Um argumento comum na literatura, conhecido como a Curva de Kuznets Ambiental, é o de que o aumento da renda per capita provoca uma demanda maior por qualidade ambiental. Logo, a degradação poderia ser diminuída face o aumento na renda.

Assim, através da decomposição estrutural de um modelo de insumo-produto foram contrapostos os efeitos do aumento do consumo das famílias ${ }^{1}$, do avanço tecnoló-

\footnotetext{
A rigor o conceito adotado é o de domicílio, que não requer a existência de laços afetivos ou de consanguinidade entre os moradores.
} 
gico e das mudanças nas cestas de consumo sobre a variação das emissões de gases do efeito estufa (GEE), tomadas como proxy para a pressão ambiental. O período analisado vai de 1995 a 2009.

O artigo conta com mais cinco seções, além desta nota introdutória. A próxima seção apresenta a evolução do padrão de consumo das famílias brasileiras, conforme os dados da Pesquisa de Orçamentos Familiares. Daí é possível inferir o movimento de reforço da economia de massas no Brasil, bem como as grandes diferenças existentes no padrão de consumo por classe de renda. A terceira seção traz um apanhado de estudos publicados sobre o mesmo tema e com abordagens semelhantes. O recorte foi a presença de exercício empírico e que preferencialmente utilizasse o insumo produto ou outra ferramenta de análise multissetorial. A quarta seção apresenta a decomposição estrutural e a base de dados utilizada. Na sequência, os resultados são apresentados e comentados, com destaque para a decomposição da variação das emissões relacionadas aos componentes da demanda final, com maior atenção ao consumo das famílias. A última seção traz as considerações finais.

\section{ALTERAÇÕES DO PERFIL DE CONSUMONAS ÚLTIMAS DUAS DÉCADAS}

A evolução das despesas das famílias brasileiras pode ser visualizada nos dados da Pesquisa de Orçamentos Familiares (POF) do IBGE. A pesquisa está em sua quarta edição e desde seu lançamento sofreu uma série de ajustes metodológicos. O período coberto pela pesquisa é mais facilmente apreendido se dividido em dois blocos. O primeiro compara os resultados da POF de 1987/88 aos de 1995/96 (Tabela 1) e se refere aos gastos domiciliares em 13 regiões metropolitanas do país. A seguir, a comparação é entre as pesquisas de 2002/03 e 2008/09 (Tabela 2). Neste caso, a abrangência da amostra é nacional.

No primeiro período houve um aumento significativo dos gastos com habitação, serviços de educação e saúde, além da aquisição de veículos. O item alimentação diminuiu seu peso relativo, assim como o vestuário. A desagregação da categoria habitação indica que o aumento das despesas deveu-se, principalmente, aos itens aluguel e impostos e taxas. No período em questão houve a abertura comercial e a estabilização monetária da economia. Os dois processos concorreram para a recuperação do poder de compra da população e para o deslocamento das despesas dos bens industrializados para os serviços - em parte, uma consequência das variações dos preços relativos. Frente à concorrência estrangeira e a taxa de câmbio apreciada, os bens industrializados tornaram-se relativamente mais baratos, e houve um encarecimento dos serviços. 
Tabela 1 - Percentual da despesa média mensal familiar por tipo de despesa, 1987 e 1995

\begin{tabular}{|c|c|c|c|}
\hline & 1987 & 1995 & $\operatorname{Var}(\%)$ \\
\hline Desembolso global & 100,00 & 100,00 & \\
\hline Despesas correntes & 84,50 & 81,26 & 0,04 \\
\hline Despesas de consumo & 73,87 & 71,14 & 0,04 \\
\hline Alimentação & 18,72 & 16,61 & 0,11 \\
\hline Habitação & 15,71 & 20,51 & $-0,31$ \\
\hline Vestuário & 9,54 & 4,70 & 0,51 \\
\hline Transporte & 11,05 & 9,81 & 0,11 \\
\hline Higiene e cuidados pessoais & 1,41 & 1,35 & 0,04 \\
\hline Assistência à saúde & 5,31 & 6,50 & $-0,22$ \\
\hline Educação & 2,67 & 3,46 & $-0,30$ \\
\hline Recreação e cultura & 3,18 & 2,51 & 0,21 \\
\hline Fumo & 1,11 & 1,00 & 0,10 \\
\hline Serviços pessoais & 1,15 & 1,16 & $-0,01$ \\
\hline Despesas diversas & 4,00 & 3,51 & 0,12 \\
\hline Outras (despesas correntes) & 10,63 & 10,12 & 0,05 \\
\hline Aumento do ativo & 14,07 & 16,92 & $-0,20$ \\
\hline Veículo & 5,54 & 8,63 & $-0,56$ \\
\hline Imóvel (aquisição) & 3,76 & 3,00 & 0,20 \\
\hline Imóvel (reforma) & 4,54 & 4,62 & $-0,02$ \\
\hline Outros investimentos & 0,24 & 0,66 & $-1,75$ \\
\hline Diminuição do passivo & 1,43 & 1,82 & $-0,27$ \\
\hline
\end{tabular}

Fonte: IBGE (1988, 1996), POF/IBGE (1987/88, 1995/96).

No período seguinte, entre as POF de 2002 e 2008, os preços relativos exibiram outra dinâmica. A política macroeconômica já adotava o câmbio flutuante, as exportações aumentaram substancialmente, sobretudo das commodities agrícolas e minerais, que encontraram preços em ascensão no mercado internacional. O movimento esperado após a desvalorização de 1999 era o deslocamento da demanda dos bens comercializáveis para os não comercializáveis. O saldo foi o aumento do preço relativo dos alimentos, especialmente a partir de 2006, e dos serviços, enquanto os bens industrializados ficaram relativamente mais acessíveis. O movimento dos preços é inequívoco: o barateamento relativo dos bens industrializados. As causas mais gerais apontadas na literatura são: a tendência ao aumento da produtividade dos setores industriais face os setores de serviços (Baumol, 1967) ou, ao menos, dos serviços "não industrializáveis" (Kander, 2005; Henriques e Kander, 2010), e a trajetória tecnológica da economia (Lorentz e Savona, 2008). O comparativo das despesas das famílias brasileiras entre 2002 e 2008 pode ser consultado na Tabela 2. 
Tabela 2 - Percentual da despesa média mensal familiar por tipo de despesa, 2002 e 2008

\begin{tabular}{lccc}
\hline \multirow{2}{*}{ Tipo de despesa } & \multicolumn{2}{c}{ \% da despesa } & Var (\%) \\
\cline { 2 - 3 } & $\mathbf{2 0 0 2}$ & $\mathbf{2 0 0 8}$ & \\
\hline Despesa total & 100 & 100 & \\
Despesas correntes & 93,3 & 92,1 & $-0,01$ \\
Despesas de consumo & 82,1 & 81,3 & $-0,01$ \\
Alimentação & 16,9 & 16,1 & $-0,05$ \\
Habitação & 29 & 29,2 & 0,01 \\
Vestuário & 4,6 & 4,5 & $-0,02$ \\
Transporte & $\mathbf{1 5 , 1}$ & $\mathbf{1 6}$ & $\mathbf{0 , 0 6}$ \\
Urbano & 2,4 & 2,2 & $-0,08$ \\
Combustível - gasolina e álcool & 3,2 & 3,1 & $-0,03$ \\
Aquisição de veículos & $\mathbf{5 , 9}$ & $\mathbf{6 , 9}$ & $\mathbf{0 , 1 7}$ \\
Outras & 3,6 & 3,7 & 0,03 \\
Higiene e cuidados pessoais & 1,8 & 1,9 & 0,06 \\
Assistência à saúde & 5,7 & 5,9 & 0,04 \\
Educação & $\mathbf{3 , 3}$ & $\mathbf{2 , 5}$ & $\mathbf{- 0 , 2 4}$ \\
Recreação e cultura & $\mathbf{1 , 9}$ & $\mathbf{1 , 6}$ & $\mathbf{- 0 , 1 6}$ \\
Fumo & 0,6 & 0,4 & $-0,33$ \\
Serviços pessoais & 0,8 & 0,9 & 0,13 \\
Despesas diversas & 2,3 & 2,4 & 0,04 \\
Outras despesas correntes & 11,2 & 10,9 & $-0,03$ \\
Aumento do ativo & 4,7 & 5,8 & 0,23 \\
Diminuição do passivo & 2 & 2,1 & 0,05 \\
\hline
\end{tabular}

Fonte: POF/IBGE (2002/2009).

Houve relativa estabilidade da composição dos gastos entre 2002 e 2008. Os itens aquisição de automóveis, transporte e assistência à saúde aumentaram sua participação. O comportamento inverso foi observado nos gastos com educação.

Além da variação dos preços relativos, a sociedade brasileira vivenciou outras mudanças significativas nas últimas duas décadas. A renda domiciliar per capita aumentou substancialmente, o país iniciou o processo de transição demográfica, o acesso à educação e informação aumentou, bem como o número de domicílios chefiados por mulheres (Neri, 2012; Carvalho e Alves, 2012). Houve uma importante formalização do mercado de trabalho e ainda a elevação do salário mínimo em termos reais (Neri, 2012; Dedecca et al., 2014).

Os estudos sobre os dados da POF informam, por exemplo, que o perfil etário das famílias pode ser decisivo para a definição da parcela dos gastos com alimentação, ou que a baixa proporção dos gastos dos mais pobres com habitação está associada à baixa utilização de serviços domésticos, enquanto o gasto com aluguel correlaciona-se mais à idade do chefe de família do que à renda familiar per capita (Bertasso, Silveira e Ma- 
galhães, 2007). O sexo da pessoa de referência parece não ter tanto efeito sobre a composição dos gastos (Carvalho e Alves, 2012). As despesas com o transporte urbano são mais significativas entre as famílias de menor renda, e o gasto com o veículo próprio é mais importante entre as famílias de renda mais elevada (Bertasso, Silveira e Magalhães, 2007).

A renda per capita, o sexo do chefe da família, o tamanho da família e sua composição etária alteram a probabilidade de aquisição de bens duráveis (Bertasso, 2007). Por sinal, o acesso a estes bens aumentou entre as famílias mais pobres. O percentual de domicílios atendidos por serviços de iluminação elétrica e telefonia fixa, e de posse do conjunto de bens que inclui computador, geladeira, televisor em cores e máquina de lavar, aumentou de 13,6\% em 2003 para 22,5\% em 2009 (PNAD/IBGE, 2009). O padrão mais recente das despesas da família brasileira, por faixa de renda, pode ser visualizado na Tabela 3 .

Tabela 3 - Distribuição percentual da despesa monetária e não monetária média mensal familiar, por classes de rendimento, segundo os tipos de despesa e variação patrimonial, Brasil, 2009

\begin{tabular}{|c|c|c|c|c|c|c|c|c|}
\hline & Total & $\begin{array}{c}\text { Até } \\
\mathrm{R} \$ \mathbf{8 3 0}\end{array}$ & $\begin{array}{c}\text { Mais de } \\
830 \text { a } \\
\text { R\$ } 1.245\end{array}$ & $\begin{array}{c}\text { Mais de } \\
\text { R\$ } 1.245 \mathrm{a} \\
\mathrm{R} \$ 2.490\end{array}$ & $\begin{array}{c}\text { Mais de } \\
\text { R\$2.490 a } \\
\text { R\$4.150 }\end{array}$ & $\begin{array}{c}\text { Mais de } \\
\text { R\$ } 4.150 \mathrm{a} \\
\mathrm{R} \$ 6.225\end{array}$ & $\begin{array}{c}\text { Mais de } \\
\text { R\$ } 6.225 \text { a } \\
\text { R\$ } 10.375\end{array}$ & $\begin{array}{c}\text { Mais de } \\
\text { R\$10.375 }\end{array}$ \\
\hline Despesa total & 100 & 100 & 100 & 100 & 100 & 100 & 100 & 100 \\
\hline Despesas correntes & 92,1 & 96,9 & 96,4 & 95 & 92,9 & 90 & 92 & 87,1 \\
\hline Despesas de consumo & 81,3 & 93,9 & 92 & 88,7 & 84,2 & 79,2 & 78,2 & 67,2 \\
\hline Alimentação & 16,1 & 27,8 & 24,8 & 20,9 & 16,7 & 13,7 & 11,7 & 8,5 \\
\hline Habitação & 29,2 & 37,2 & 36,5 & 33,3 & 30,2 & 27,6 & 25,1 & 22,8 \\
\hline Vestuário & 4,5 & 5,4 & 5,2 & 5,3 & 5 & 4,2 & 4 & 3,2 \\
\hline Transporte & 16 & 9,7 & 11,1 & 13,7 & 16,6 & 17,5 & 19,8 & 17,7 \\
\hline Transporte urbano & 2,2 & 3,8 & 4,2 & 3,5 & 2,7 & 1,6 & 1,2 & 0,6 \\
\hline Gasolina - veículo próprio & 2,6 & 1,4 & 1,7 & 2,5 & 3,2 & 3,2 & 3 & 2,4 \\
\hline Álcool - veículo próprio & 0,5 & 0,1 & 0,2 & 0,3 & 0,5 & 0,7 & 0,7 & 0,5 \\
\hline Manutenção e acessórios & 1,7 & 0,9 & 1 & 1,6 & 2 & 2 & 1,8 & 1,6 \\
\hline Aquisição de veículos & 6,9 & 2,4 & 3 & 4,5 & 6,5 & 8 & 10,3 & 9,4 \\
\hline Viagens esporádicas & 1,2 & 0,8 & 0,8 & 0,8 & 1 & 1,1 & 1,6 & 2 \\
\hline Outras & 0,8 & 0,3 & 0,3 & 0,5 & 0,7 & 0,9 & 1,2 & 1,1 \\
\hline Higiene e cuidados pessoais & 1,9 & 2,8 & 2,7 & 2,6 & 2,1 & 1,8 & 1,5 & 1 \\
\hline Assistência à saúde & 5,9 & 5,5 & 6 & 6,1 & 5,9 & 5,7 & 6,1 & 5,6 \\
\hline Educação & 2,5 & 0,9 & 1,2 & 1,6 & 2,4 & 3 & 4 & 2,9 \\
\hline Recreação e cultura & 1,6 & 1,1 & 1,3 & 1,5 & 1,6 & 1,8 & 1,9 & 1,7 \\
\hline Fumo & 0,4 & 0,9 & 0,8 & 0,7 & 0,5 & 0,3 & 0,2 & 0,2 \\
\hline Serviços pessoais & 0,9 & 0,8 & 0,8 & 1 & 1 & 1 & 1 & 0,8 \\
\hline Despesas diversas & 2,4 & 1,7 & 1,7 & 2 & 2,3 & 2,5 & 2,8 & 2,8 \\
\hline Outras despesas correntes & 10,9 & 3,1 & 4,4 & 6,4 & 8,7 & 10,8 & 13,9 & 19,9 \\
\hline Aumento do ativo & 5,8 & 2,2 & 2,3 & 3,2 & 4,9 & 7,7 & 5,6 & 10,5 \\
\hline Diminuição do passivo & 2,1 & 0,9 & 1,3 & 1,8 & 2,3 & 2,3 & 2,4 & 2,4 \\
\hline
\end{tabular}


Para as três primeiras faixas de renda, as categorias de consumo mais associadas às necessidades primárias (alimentação e habitação) representam mais da metade das despesas totais. Conforme esperado, nas duas categorias o aumento da renda é acompanhado da queda no peso relativo da despesa. A direção inverte-se nos gastos com transporte, principalmente, em função da aquisição de veículos, que aumenta sua participação, enquanto o peso do gasto com o transporte urbano diminui. Os serviços de educação, assistência à saúde, as viagens esporádicas e a recreação e cultura também estão mais presentes na despesa total à medida que aumenta a faixa de renda. Os dados indicam que o consumo discricionário é em parte direcionado aos serviços, menos intensivos em recursos naturais, mas também aos bens de consumo durável como o automóvel, e ao consumo de combustíveis.

Ex-post é comum classificar o crescimento da economia brasileira na primeira década de 2000 como resultante do incentivo ao consumo das famílias pelo aumento do crédito, do salário mínimo e das transferências governamentais, aliada à alta nos preços das commodities agrícolas e minerais exportadas (Dedecca et al., 2014; Barros, 2008). Outro possível consenso é de que o ciclo econômico favoreceu principalmente às camadas mais pobres da população (Neri, 2012; Kageyama e Hoffman, 2004). Com efeito, a taxa de pobreza recuou de $41 \%$ para 21\%, desde 1990 (IBGE, 2012) 2 $^{\text {Neste }}$ contexto de reforço da economia de massas, o fato mais destacado é o aumento do acesso da população aos bens de consumo e melhores condições materiais.

\section{PRESSÃO AMBIENTAL E CONSUMO DAS FAMÍLIAS}

A maior parte dos estudos que relacionam o consumo à pressão ambiental assume que as preferências dos consumidores são dadas e que determinam o padrão de consumo dos indivíduos e famílias. Este é o caso, por exemplo, dos trabalhos que procuram identificar grupos relativamente homogêneos de consumidores a partir dos tipos de gastos que realizam e de outras variáveis socioeconômicas, como a renda per capita, o número de filhos, o tamanho do domicílio ou a região em que residem. Em geral, a literatura identifica uma correlação positiva entre a renda e a pressão ambiental, muito embora o grau da associação entre as variáveis possa mudar significativamente a de-

\footnotetext{
2 Segundo IBGE (2012), a taxa de pobreza mede o percentual de pessoas na população total com renda domiciliar per capita inferior à linha de pobreza. A linha de pobreza aqui considerada é o dobro da linha de extrema pobreza, uma estimativa do valor de uma cesta de alimentos com o mínimo de calorias necessárias para suprir adequadamente uma pessoa, com base em recomendações da Food and Agriculture Organization (FAO) e da Organização Mundial da Saúde (OMS). Os dados são da PNAD.
} 
pender do impacto ambiental avaliado. Frequentemente os estudos apontam que a pressão ambiental diminui, em termos relativos, ou seja, por unidade monetária de consumo, quando a renda aumenta. Todavia, em nenhum momento a pressão ambiental torna-se decrescente.

Por exemplo, Baiocchi, Minx e Hubacek (2010) associaram diferentes estilos de vida às emissões de carbono no Reino Unido, para o ano de 2005. Os autores conciliaram um banco de dados típico de pesquisas de marketing, em que os consumidores são segmentados por variáveis geográficas e sociais, à emissão total de carbono dos produtos, estimada via análise de insumo-produto. O resultado é que houve grande variação nas emissões, até o fator 3, devido ao estilo de vida. Não houve redução absoluta das emissões quando aumentou o nível de renda, ao contrário, a elasticidade renda das emissões teve formato de " $U$ ”. Segundo os autores, casas e famílias maiores aumentaram as emissões. A educação, o uso da internet e a presença de crianças as reduziram. Quando consideradas as categorias de consumo, a habitação, especialmente em função dos sistemas de calefação, o transporte e a alimentação constituíram os principais itens responsáveis pelas emissões de carbono no consumo das famílias.

Já Munskgaard et al. (2005) discutiram os impactos ambientais do consumo nos domicílios holandeses através da integração do insumo-produto às pesquisas domiciliares e a um conjunto de indicadores da qualidade ambiental. O resultado foi o esperado. Famílias com maior renda exerceram menor pressão relativa, porém maior pressão absoluta. Todavia, a ordem das famílias que mais pressionaram o meio ambiente não foi fixa e, de fato, mudou para cada tipo de impacto ambiental. Por exemplo, as emissões nocivas à camada de ozônio, os requerimentos de materiais e a oxidação fotoquímica, foram menos intensas nos domicílios de menor renda. Famílias nas zonas rurais tiveram consumo menos amigável para o meio ambiente em termos destes mesmos indicadores e também do aquecimento global. Isto ocorreu em função das necessidades de transporte e energia. A contribuição geral para a confecção de políticas é a identificação das famílias cujo consumo impacta mais gravemente o meio ambiente.

Ainda para os domicílios holandeses, Kerkhof et al. (2009) relacionaram o consumo das famílias à mudança climática, eutrofização, acidificação e emissão de fumaça. Os dados apontaram que o aumento da despesa total aumentou a pressão ambiental; entretanto, a depender do impacto considerado, este aumento foi proporcional, menos que proporcional ou mais do que proporcional. De posse dos gastos das famílias, separadas por decis de despesas equivalente - que leva em conta o tamanho do domicílio - e das intensidades de pressão ambiental, os autores calcularam as elasticidades de emissão de poluentes em relação aos gastos das famílias. A combinação entre os bens de primeira necessidade, por exemplo, alimentação e habitação, e os bens de luxo, como combustível para viagens, foi decisiva para o impacto ambiental. Toda- 
via, a classificação dos bens em cada categoria foi arbitrária. A emissão de fumaça aumentou com a renda, pois o consumo de gasolina e viagens também aumentou, enquanto a eutrofização diminuiu, pois está mais relacionada à alimentação.

Roca e Serrano (2007) investigaram as emissões por faixa de despesa domiciliar, e as elasticidades-despesa das emissões de nove gases do efeito estufa. Os padrões de consumo domiciliares foram comparados em vintis da despesa total, por produtos, tamanho e categoria de consumo. Os autores não encontraram suporte para a hipótese do descolamento da pressão ambiental sugerido pela hipótese da Curva de Kuznets Ambiental (CKA). Houve, outra vez, apenas descolamento relativo das emissões, para todos os gases, exceto os sintéticos, o que resultou, sobretudo, do aumento do consumo de automóveis, que implicou maior intensidade de emissões para as maiores despesas. Todavia, houve diminuição no uso absoluto destes gases, o resultado deveu-se, porém, a acordos internacionais, não relacionados aos argumentos apresentados pela CKA. As categorias de consumo energia, alimentos e habitação, causaram maior pressão ambiental.

A questão distributiva relacionada à degradação ambiental foi investigada em Seroa da Motta (2002). O autor buscou responder às seguintes questões: quais são os níveis de degradação gerados por classe de renda? Quão concentrados estão estes níveis (em cada classe de renda)? Quais seriam as mudanças nestes níveis se a desigualdade de renda fosse alterada? As variáveis ambientais selecionadas estavam relacionadas ao ambiente urbano e permitiram o cálculo da pressão ambiental e das propensões marginais a degradar por classe de renda. A intensidade de poluição dos produtos consumidos pelas famílias foi obtida através da modelagem do insumo-produto. As classes com menores rendas, por possuírem maior propensão a consumir, também tinham maior propensão a poluir, já que os bens não são exclusivos para cada classe, então, o consumo é o que determina a pressão ambiental. Todavia, quando avaliada a poluição por domicílio, então, quanto mais ricos, maior a poluição, donde se conclui que o efeito escala domina o efeito da propensão marginal a poluir. Os resultados também indicaram que a concentração da poluição era menor do que a concentração da renda, o que implicava que as unidades de renda relacionadas ao consumo de bens e serviços dos mais pobres estariam ligadas a intensidades mais altas de degradação. Se os preços dos bens aumentassem em função de mecanismos de controle, a renda dos mais pobres seria mais afetada.

\section{A DECOMPOSIÇÃO DAS EMISSÕES DE $\mathrm{CO}_{2}$}

As emissões atribuídas a cada um dos componentes da demanda final nos anos considerados foram estimadas através da Análise de Decomposição Estrutural, a partir das matrizes de insumo-produto (MIP). Este procedimento é bastante difundido na literatura dos modelos estruturais aplicados a questões ambientais, formalmente: 


$$
i=m(I-A)^{-1}
$$

Em (1), $i$ é o vetor de dimensões $1 \times 42$ de intensidade de emissões indiretas, ou seja, diz respeito aos poluentes lançados na natureza no decorrer da cadeia produtiva dos bens, por unidade monetária. O vetor $m$ traz os coeficientes de emissões dos 42 setores de atividade econômica, calculado pela razão entre as emissões e o valor bruto da produção setorial. $\mathrm{O}$ termo $(I-A)^{-1}$ é a matriz de Leontief $(\mathbf{L})$, dada em função da matriz de coeficientes tecnológicos $A$, em que $a_{i j}$ é a quantidade do bem $i$ utilizado para a produção de uma unidade do bem $j$.

As matrizes de insumo-produto foram obtidas das Tabelas de Recursos e Usos (TRU) do IBGE. Os dados de 1995 foram trazidos a valores de 2009 conforme o deflator implícito da demanda total, calculado a partir das próprias TRU, divulgadas a preços correntes e a preços do ano anterior. As matrizes foram tomadas a preços básicos, as margens de comércio, transportes, impostos e importações, foram deduzidas das TRU conforme o procedimento descrito em Guilhoto e Sesso Filho (2005, 2010). As emissões indiretas de GEE associadas ao componente $n$ da demanda final $(f)$ foram calculadas, em cada ano, a partir da equação básica do insumo produto:

$$
e^{n}=m(1-A)^{-1} f^{n}
$$

A cada subperíodo a variação das emissões entre os subperíodos foi decomposta em:

$$
\Delta e^{c}=\left(\frac{1}{2}\right)\left(\Delta i f_{0}+\Delta i c f_{1}\right)+\left(\frac{1}{2}\right)\left(i_{0} \Delta f+i_{1} \Delta f\right)
$$

A primeira parcela da soma mostra o efeito tecnológico derivado das mudanças na intensidade das emissões setoriais, seja em função de alterações nos coeficientes da matriz de Leontief, pela substituição de insumos ou ganhos de produtividade, seja pela mudança nos coeficientes de emissão. A segunda parcela da soma traz o efeito demanda, decorrente das alterações na demanda final. A variação das emissões em resposta à mudança no padrão de consumo das famílias foi tomada como:

$$
f^{c}=k_{t} b_{t}
$$

Em (4), $f^{c}$ é o vetor de consumo das famílias, $k$ é a participação de cada bem no consumo total agregado. Logo, uma decomposição do consumo equivale a:

$$
\Delta f^{c}=\left(\frac{1}{2}\right)(\Delta b)\left(k_{1}+k_{0}\right)+\left(\frac{1}{2}\right)(\Delta k)\left(b_{1}+b_{0}\right)
$$


A primeira parcela da soma mostra o efeito da mudança na escala de consumo, enquanto a segunda parcela revela o efeito da alteração na composição do vetor de consumo entre os diferentes bens e serviços.

A opção pelo modelo de Leontief significa que a responsabilidade pelos lançamentos de GEE foi atribuída aos consumidores dos bens e serviços e não a seus produtores, já que as emissões são somadas a montante na cadeia produtiva. Esta opção é justificada pela centralidade dada ao consumo das famílias neste trabalho. Afinal, dois terços do PIB são destinados a esse consumo, que é em si uma medida do nível de conforto material, ou ao menos da opulência material da população. Ademais, o comércio internacional pode insinuar o abatimento das emissões locais de um país enquanto aumentam as emissões totais para o atendimento da sua demanda final. Ou seja, um país pode substituir a produção doméstica pela importação de produtos intensivos em GEE. A diminuição de 5\% nas emissões do Reino Unido entre 1990 e 2004 converte-se em um aumento de $15 \%$ quando considerado o comércio internacional (Druckman e Jackson, 2009). Embora não seja esse o caso brasileiro, já que o país é exportador líquido de recursos naturais (Machado et al., 2001; Young e Barbosa Filho, 1998), a responsabilização dos consumidores é mais adequada ao caráter global das emissões.

A obtenção dos vetores de emissões setoriais exigiu a compatibilização dos dados do Inventário Brasileiro de Emissões...(MCTI, 2010) e das Estimativas Anuais de Emissões de Gases de Efeito Estufa no Brasil (MCTI, 2013) aos dados da MIP. Foram tomados apenas os lançamentos de $\mathrm{CO}_{2}, \mathrm{~N}_{2} \mathrm{O}$ e $\mathrm{CH}_{4}$, que somam mais de $90 \%$ dos GEE. A mudança no uso da terra e florestas MUTF não foi considerada, em função da sua menor aderência ao ciclo econômico. A segunda parte do Inventário Brasileiro de Emissões traz as estimativas das emissões de GEE entre 1990 e 2005. As informações foram apresentadas segundo as duas metodologias sugeridas pelo Intergovernmental Panel on Climate Change (IPCC). A abordagem top-down, em que a oferta total de bens cuja produção ou consumo resultam em emissões é usada como parâmetro para estimar o volume de gases lançado na atmosfera, e a abordagem bottom-up, em que este volume é obtido entre os setores produtores ou consumidores responsáveis pelas emissões.

Quando um setor inventariado correspondeu a mais de um setor da MIP, a distribuição das emissões ocorreu conforme o valor relativo da produção ou consumo dos setores da MIP dos bens inventariados. Ou seja, os fluxos da produção ou consumo das atividades econômicas, captados em valores monetários nas Tabelas de Recursos e de Usos do IBGE, foram tomados como proxies do fluxo de emissões.

Por exemplo, as emissões de $\mathrm{CO}_{2}$ resultantes da queima de combustíveis fósseis pelo setor energético foram distribuídas entre os setores MIP de Extração de petróleo, gás..., Refino do petróleo..., Fabricação de produtos químicos diversos e Serviços in- 
dustriais de utilidade pública, conforme o consumo destas atividades dos respectivos combustíveis fósseis obtidos da Tabela de Usos, donde se obteve afinal o consumo de cada combustível. A identificação dos setores da MIP que compuseram o setor energético do inventário exigiu que as informações do Balanço Energético Nacional (BEN) fossem adequadas aos setores-MIP. Para a queima de combustíveis fósseis o Inventário Brasileiro de Emissões seguiu a classificação setorial do BEN.

Os códigos CNAE 1.0, trasladáveis para o Sistema de Contas Nacionais, foram usados para a identificação dos setores da MIP relacionados a cada setor do BEN. A partir daí é que as emissões totais da queima de combustíveis fósseis foram desagregadas conforme o fluxo monetário das TRU.

O setor não energético do BEN diz respeito à produção de derivados não energéticos do petróleo, como graxas lubrificantes, parafinas, asfalto e solventes (EPE, 2011). As emissões deste setor foram atribuídas ao setor de Refino do petróleo. Para a utilização dos fluxos monetários como proxy foi preciso antes a localização dos combustíveis fósseis na Lista de Produtos da Indústria (IBGE, 2007), conforme publicação em IBGE (2007), e sua correspondência entre as atividades CNAE 1.0, e daí para os 80 produtos das TRU.

As emissões da queima de combustíveis fósseis pelo Setor público do BEN foram atribuídas sem ambiguidades ao setor Administração Pública da MIP, enquanto para os transportes a atribuição foi no setor de Transportes, conforme a compatibilização de Montoya et al. (2013), traduzida para o SCN 43. O setor de Comércio do BEN teve suas emissões distribuídas pelo mesmo procedimento.

Nos processos industriais as emissões ocorrem na indústria siderúrgica, na química, e na produção de alumínio e de minerais não metálicos. No caso da siderurgia, devido principalmente ao processo de redução do minério de ferro nas usinas integradas (MCTI, 2010). Na indústria química os GEE são gerados na obtenção de diversos químicos e petroquímicos, como subprodutos das reações físico-químicas (MCTI, 2010). O alumínio primário é obtido da redução eletrolítica do óxido de alumínio, processo que libera $\mathrm{CO}_{2}$ (MCTI, 2010). No setor de minerais não metálicos, o cimento tem como matéria-prima o clínquer, cuja produção resulta em lançamentos de $\mathrm{CO}_{2}$ (MCTI, 2010). Já a formação da cal ocorre no aquecimento a elevadas temperaturas do calcário para a decomposição dos carbonatos, o que libera $\mathrm{CO}_{2}$ (MCTI, 2010). De modo semelhante o calcário e a dolomita são aquecidos na produção do vidro e do magnésio (MCTI, 2010). Assim, nos processos industriais as emissões foram redistribuídas entre os setores da MIP conforme a produção dos bens que as acarretam, tendo como proxy o fluxo monetário da assinalado na Tabela de Recursos do IBGE.

Vale ressaltar que as emissões do consumo de carvão mineral pela indústria siderúrgica foram alocadas nos processos industriais, conforme o Inventário Brasileiro de 
Emissões. O tratamento de resíduos causa emissões em função da disposição final e incineração dos resíduos sólidos urbanos, e do lançamento de efluentes domésticos, comerciais e industriais. Como os resíduos sólidos são gerados pós-consumo, suas emissões não foram realocadas entre os setores produtivos. Logo, levando-se em conta apenas o $\mathrm{CO}_{2}, \mathrm{o} \mathrm{CH}_{4}$ e o $\mathrm{N}_{2} \mathrm{O}$, e excluídas as emissões da MUTF e do tratamento de resíduos, o total analisado representa 74\% das emissões totais de $\mathrm{CO}_{2}$ e em 2010.

\subsection{BASE DE DADOS}

O Gráfico 1 traz as emissões brasileiras de GEE entre os anos de 1990 e 2010, com base nas Estimativas Anuais de Gases do Efeito Estufa, publicadas pelo Ministério da Ciência, Tecnologia e Inovação em 2013. As estimativas brasileiras seguiram a metodologia recomendada pelo IPCC para a elaboração dos inventários nacionais de emissão de GEE.

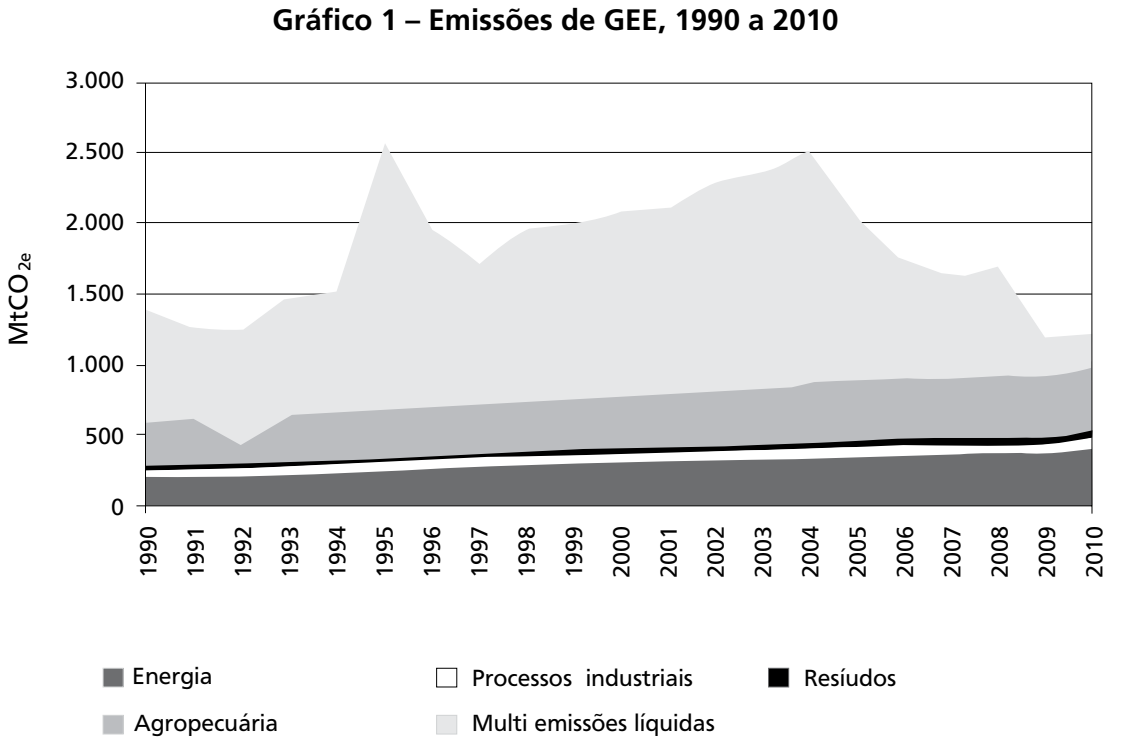

Notas: (a) Os gases inventariados nestas estimativas foram dióxido de carbono $\left(\mathrm{CO}_{2}\right)$, o metano $\left(\mathrm{CH}_{4}\right)$, óxido nitroso $\left(\mathrm{N}_{2} \mathrm{O}\right)$, os hidrofluorcarbonos (HFC's), perfluocarbonos (CF's), e o hexafluoreto de enxofre ( $\left.\mathrm{SF}_{6}\right)$; (b) Os gases foram convertidos em $\mathrm{CO}_{2}$ equivalente conforme a potencial contribuição para o aquecimento global (GWP); (c) MUTF é mudança no uso da terra e florestas.

Fonte: MCTI (2013).

O setor de Energia reúne as emissões da queima de combustíveis fósseis e fugitivas da produção de petróleo, gás e carvão mineral. No caso dos processos industriais as 
emissões advêm dos processos produtivos em si, exclusive aquelas decorrentes da queima de combustíveis, contabilizadas na categoria energia ${ }^{3}$. $\mathrm{Na}$ agropecuária foram consideradas as emissões da fermentação entérica dos rebanhos, do cultivo de arroz, do manejo de dejetos animais, dos solos agrícolas e da queima de resíduos agrícolas. Na MUTF o saldo entre as remoções e emissões entre os diversos usos da terra, além da aplicação de calcário e queima da biomassa (MCTI, 2013).

Há dois movimentos bastante marcados na evolução das emissões brasileiras. A variação do total em função do comportamento da MUTF, com a diminuição progressiva desde o pico em 2004, e o aumento continuado das emissões pelas demais fontes, sobretudo a agropecuária e geração de energia. O valor bruto da produção setorial e os coeficientes de emissões podem ser visualizados na Tabela A.1, no Apêndice. Houve redução no coeficiente de emissões médio da economia. $\mathrm{O}$ valor bruto da produção (VBP) cresceu $66 \%$ no período enquanto o lançamento de $\mathrm{CO}_{2}$ e subiu $34 \%$.

\section{RESULTADOS E DISCUSSÃO}

No início dos anos 1990 a hipótese da Curva de Kuznets Ambiental (CKA) chamou atenção para os canais pelos quais o crescimento econômico interfere sobre os recursos naturais. À semelhança do padrão defendido por Simon Kuznets (1955) para a relação entre o crescimento e a desigualdade na distribuição de renda, a CKA também pressupõe o aumento da poluição e sua posterior reversão a partir de certo nível de renda per capita.

Ao passar de economias pobres e agrárias à industrialização, os países elevam a pressão sobre o meio ambiente pelo próprio aumento da escala de transformação. A seguir, a níveis de renda suficientemente altos, a economia passa à fase em que os serviços, menos intensivos em recursos naturais e poluição, passam compor a maior parte do produto (Dinda, 2004). O que dá o formato da curva ora é a mudança nas preferências dos indivíduos, pois, satisfeitas as necessidades materiais, o consumo desloca-se para bens menos intensivos em recursos naturais e a proteção ambiental passa a ser mais valorizada, ora é o fator tecnológico, como a substituição de insumos e o ganho de produtividade, ou ambos.

No Brasil, o crescimento recente foi impulsionado pelas exportações, que cresceram $116 \%$ ante um aumento de $66 \%$ do PIB, entre 1995 e 2009. Todavia, os setores

3 O coque de carvão mineral utilizado na indústria siderúrgica foi atribuído à categoria "processos industriais" (MCTI, 2010). O coque é simultaneamente matéria-prima e fonte de energia na siderurgia (IAB, 2011) 
exportadores são também mais intensivos em recursos naturais, como é o caso da agropecuária e indústria extrativa. $\mathrm{O}$ impacto do crescimento brasileiro sobre as emissões de GEE pode ser visualizado na Tabela 6, para o Brasil entre 1995 e $2009^{4}$.

Tabela 6 - Variação das emissões por componente da demanda final, de 1995 a 2009, em $\mathrm{MtCO}_{2 \mathrm{e}}$

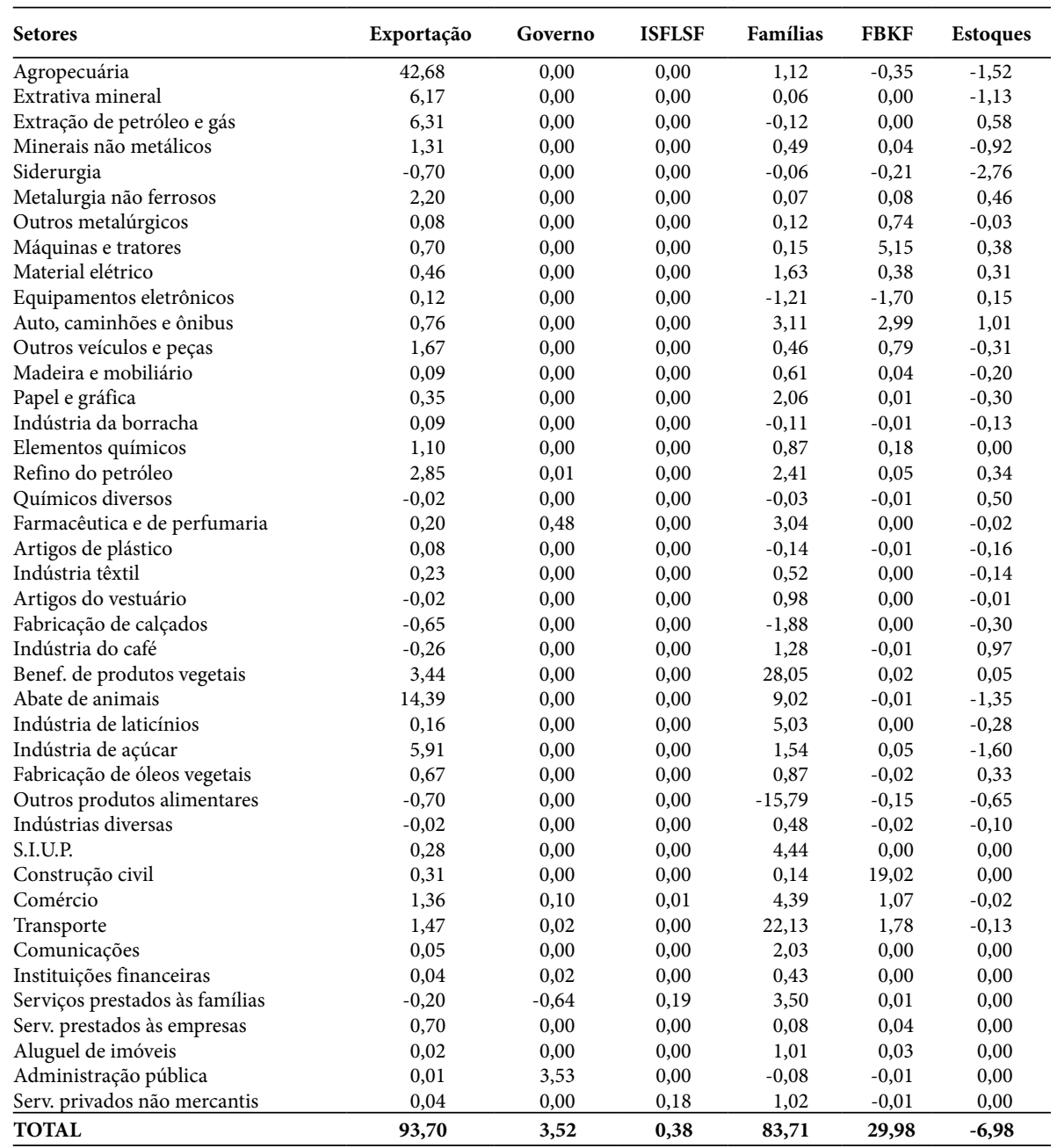

Fonte: Elaboração própria.

4 Cabe a ressalva de que o objetivo do artigo não é testar a CKA, definida para o longo prazo. Apenas alguns de seus canais de interação entre o crescimento econômico e o meio ambiente foram tomados como guias nesta seção. 
O aumento total das emissões foi de $204 \mathrm{MtCO}_{2 \mathrm{e}}$, a maior parte em função do aumento das exportações (46\%), sobretudo da agropecuária (21\%), potencializada pela dinâmica dos preços relativos no período em questão. $\mathrm{O}$ consumo das famílias que respondia por $67 \%$ do $\mathrm{CO}_{2} \mathrm{e}$ em 1995 , no último ano essa participação alcançava $60 \%$. Neste vetor, o crescimento de $21 \%$ (83 Mt) deveu-se principalmente aos setores de transportes e beneficiamento de produtos vegetais. Houve queda expressiva das emissões dos outros produtos alimentares. Em 2009, a agropecuária representou 23\% das emissões do consumo das famílias, os transportes $14 \%$ e o abate de animais outros $12 \%$.

Em linhas gerais, o resultado reflete a maior concentração das exportações brasileiras em produtos intensivos em GEE, conforme já apontado em outros trabalhos (Young e Barbosa-Filho, 1998; Lustosa, 2001; Machado et al., 2001), o peso da produção de alimentos dentre as fontes de GEE, e a tendência de aumento das emissões dos transportes, acompanhando a elevação da renda.

O efeito tecnológico atuou no sentido de redução das emissões, em de $87 \mathrm{MtCO}_{2 \mathrm{e}}$, sobretudo, em função da redução dos GEE originados na agropecuária e demais setores ligados à produção de alimentos. Nos restante das atividades as quedas foram pouco expressivas, exceto os serviços prestados às famílias, que, no entanto, adquirem muitos produtos da indústria alimentícia e agropecuária.

O efeito composição também contribuiu para a queda dos GEE, outra vez, em função dos produtos ligados à alimentação, resultado esperado diante do crescimento da renda, dada a típica inelasticidade da demanda dos produtos do gênero. $O$ sentido contrário foi verificado nos serviços prestados às famílias, cujo consumo tende a aumentar com a elevação da renda.

Finalmente, a maior escala do consumo provocou um aumento das emissões totais que superou bastante a soma do efeito tecnológico ao efeito composição. Para os outros produtos alimentares a escala de consumo não foi capaz de reverter ou quase anular o abatimento das emissões dos outros dois efeitos. O oposto aconteceu com o setor de beneficiamento de produtos vegetais. Este resultado sugere que a mudança nos hábitos de consumo deslocou parte da demanda dos alimentos para os outros produtos para aqueles beneficiados e possivelmente para a alimentação fora de casa, como indica o crescimento dos GEE nos serviços prestados às famílias. A Tabela 7 apresenta a estimativa do efeito tecnológico, composição e escala, por setores de atividade econômica. 
Tabela 7 - Variação das emissões totais do consumo final das famílias, por tipo de efeito, entre 1995 e 2009

\begin{tabular}{|c|c|c|c|c|}
\hline SETORES & $\begin{array}{c}\text { Efeito } \\
\text { tecnológico }\end{array}$ & $\begin{array}{c}\text { Efeito } \\
\text { composição }\end{array}$ & $\begin{array}{l}\text { Efeito } \\
\text { escala }\end{array}$ & $\begin{array}{c}\text { Efeito } \\
\text { total }\end{array}$ \\
\hline Agropecuária & $-32,76$ & $-24,69$ & 58,57 & 1,12 \\
\hline Extrativa mineral & 0,02 & $-0,03$ & 0,07 & 0,06 \\
\hline Extração de petróleo e gás & $-0,07$ & $-0,15$ & 0,10 & $-0,12$ \\
\hline Minerais não metálicos & 0,55 & $-0,77$ & 0,71 & 0,49 \\
\hline Siderurgia & 0,01 & $-0,13$ & 0,06 & $-0,06$ \\
\hline Metalurgia não ferrosos & 0,00 & 0,04 & 0,02 & 0,07 \\
\hline Outros metalúrgicos & $-0,09$ & $-0,12$ & 0,33 & 0,12 \\
\hline Máquinas e tratores & 0,00 & $-0,05$ & 0,20 & 0,15 \\
\hline Material elétrico & $-0,45$ & 0,65 & 1,43 & 1,63 \\
\hline Equipamentos eletrônicos & $-1,07$ & $-1,22$ & 1,08 & $-1,21$ \\
\hline Auto., caminhões e ônibus & $-2,14$ & 1,59 & 3,65 & 3,11 \\
\hline Outros veículos e peças & $-0,02$ & $-0,21$ & 0,68 & 0,46 \\
\hline Madeira e mobiliário & 0,10 & $-1,36$ & 1,87 & 0,61 \\
\hline Papel e gráfica & $-0,39$ & 0,62 & 1,83 & 2,06 \\
\hline Indústria da borracha & $-0,10$ & $-0,30$ & 0,29 & $-0,11$ \\
\hline Elementos químicos & $-0,01$ & $-1,98$ & 2,86 & 0,87 \\
\hline Refino do petróleo & $-2,86$ & $-1,71$ & 6,98 & 2,41 \\
\hline Químicos diversos & $-0,04$ & $-0,30$ & 0,30 & $-0,03$ \\
\hline Farmacêutica e de perfumaria & $-0,20$ & 0,07 & 3,16 & 3,04 \\
\hline Artigos de plástico & $-0,05$ & $-0,26$ & 0,17 & $-0,14$ \\
\hline Indústria têxtil & 0,12 & $-1,11$ & 1,51 & 0,52 \\
\hline Artigos do vestuário & 1,27 & $-2,42$ & 2,13 & 0,98 \\
\hline Fabricação de calçados & $-2,06$ & $-1,88$ & 2,06 & $-1,88$ \\
\hline Indústria do café & $-1,42$ & 0,39 & 2,31 & 1,28 \\
\hline Benef. de produtos vegetais & 8,97 & 7,85 & 11,23 & 28,05 \\
\hline Abate de animais & $-12,69$ & $-5,22$ & 26,94 & 9,02 \\
\hline Indústria de laticínios & $-3,15$ & $-2,46$ & 10,64 & 5,03 \\
\hline Indústria de açúcar & 0,22 & $-2,39$ & 3,71 & 1,54 \\
\hline Fabricação de óleos vegetais & $-1,16$ & $-2,98$ & 5,02 & 0,87 \\
\hline Outros produtos alimentares & $-17,89$ & $-12,50$ & 14,60 & $-15,79$ \\
\hline Indústrias diversas & 0,00 & $-0,11$ & 0,58 & 0,48 \\
\hline S.I.U.P. & 0,56 & 0,27 & 3,61 & 4,44 \\
\hline Construção civil & 0,00 & 0,11 & 0,03 & 0,14 \\
\hline Comércio & 1,35 & $-1,36$ & 4,41 & 4,39 \\
\hline Transporte & $-3,73$ & $-3,01$ & 28,86 & 22,13 \\
\hline Comunicações & 0,32 & 0,96 & 0,74 & 2,03 \\
\hline Instituições financeiras & $-1,48$ & 0,45 & 1,47 & 0,43 \\
\hline Serviços prestados às famílias & $-14,85$ & 3,21 & 15,15 & 3,50 \\
\hline Serv. prestados às empresas & $-0,45$ & 0,14 & 0,38 & 0,08 \\
\hline Aluguel de imóveis & $-0,43$ & 0,66 & 0,79 & 1,01 \\
\hline Administração pública & $-0,14$ & $-0,16$ & 0,22 & $-0,08$ \\
\hline Serv. privados não mercantis & $-1,23$ & 0,05 & 2,20 & 1,02 \\
\hline TOTAL & $-87,42$ & $-51,83$ & 222,96 & 83,71 \\
\hline
\end{tabular}

Fonte: Elaboração própria. 
No caso dos transportes o efeito escala teve sentido oposto e foi quase cinco vezes superior à soma dos efeitos tecnológico e composição. O modal rodoviário representou $90 \%$ das emissões em 2009 (MCTI, 2013). O consumo da gasolina automotiva cresceu 32\% entre 2000 e 2010 e o de óleo diesel, 35\% (EPE, 2011). Nos centros urbanos, levando-se em conta o número de passageiros por quilômetros percorridos, $50 \%$ do transporte foram feitos de ônibus e outros 43\%, de automóvel (Gouvello, 2010). Além da grande dependência do transporte individual, a frota de ônibus é antiga, possui tecnologia defasa quanto à poluição, e a metade tem mais de 20 anos de uso (CNT, 2014). Em 2010, os combustíveis fósseis foram 70\% do total consumido para o transporte de passageiros, o etanol foi $25 \%$ e o GNV, $4 \%$. Para o transporte de cargas a situação da frota é a mesma, 45\% dos caminhões têm mais de 20 anos de uso, e outros $20 \%$ superaram os 30 anos (Boson, 2011), mais de 90\% das emissões vem dos caminhões pesados e semipesados a diesel (MMA, 2011). A Empresa de Pesquisa Energética (EPE), ligada ao Ministério das Minas e Energia, prevê um aumento de $28 \%$ das emissões dos transportes no decênio entre 2012 e 2022.

Quanto às emissões por faixa de renda domiciliar per capita, tem-se que o aumento das emissões foi relativamente menor entre os mais afluentes, acompanhando o menor aumento das despesas em consumo. Em nenhum vintil de renda os GEE diminuíram. O Gráfico 2 ilustra essa evolução.

Gráfico 2 - Emissões domiciliares totais por vintis de renda domiciliar per capita, em 1995 e 2009

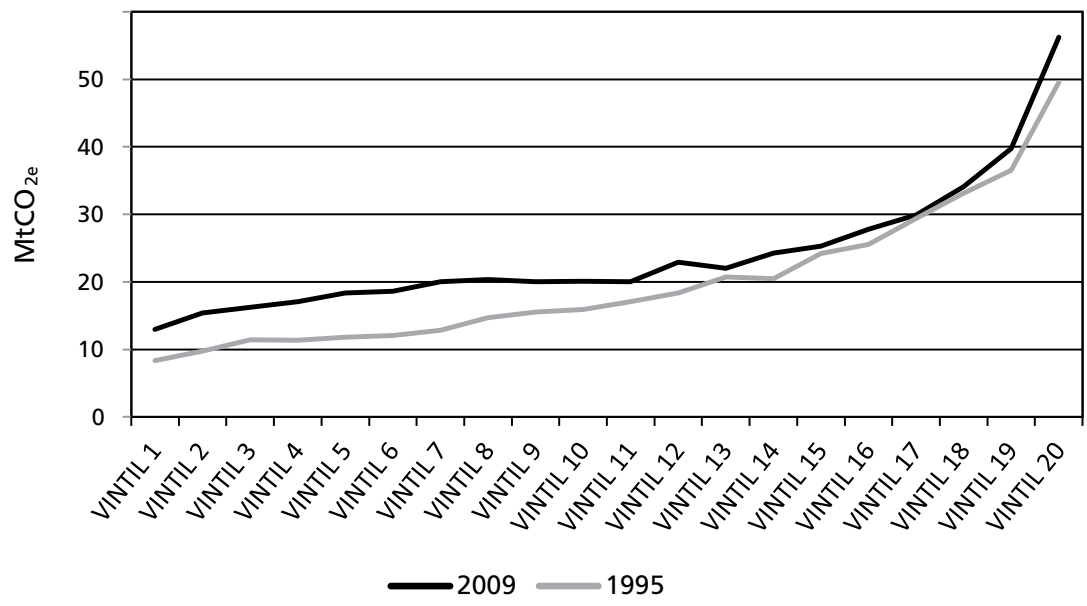

Fonte: Elaboração própria.

O impacto ambiental pode ser resumido conforme a equação I = PAT, ou seja, o impacto I equivale ao produto de uma variável de escala, por exemplo, a população 
(P), uma medida de afluência, como a renda ou a despesa em consumo per capita (A), e uma variável tecnológica, como a intensidade de emissões (T). Nas últimas duas décadas o crescimento econômico brasileiro produziu um aumento da pressão ambiental induzido pela maior afluência.

A desigualdade na geração de emissões diminuiu. Entre os domicílios, os $20 \%$ mais afluentes geraram 3,64 vezes mais GEE que os 20\% mais pobres em 1995, no ano de 2009 essa relação foi de 2,59 vezes. Se, de um lado, o crescimento e a melhor distribuição de renda são fundamentais para assegurar a todos as condições materiais adequadas, de outro, serão necessários tetos para a produção e consumo, ao menos dos bens mais intensivos em GEE, de modo que os benefícios do desenvolvimento humano sejam perenes. O que implica transformações no padrão de consumo das famílias.

Assim como em Freitas e Kaneko (2011) e Silva e Perobelli (2011), foi identificado o descolamento relativos das emissões, isto é, a intensidade de GEE por unidade do produto caiu, no entanto, em proporção insuficiente para conter o crescimento da pressão ambiental. Conforme Cohen (2002) conclui-se que mudanças significativas nas emissões de GEE, no curto-prazo, envolvem custos e/ou mudanças no estilo de vida e padrões de consumo, e que o foco na oferta e soluções tecnológicas é insuficiente para lidar com a questão ambiental.

\section{CONSIDERAÇÕES FINAIS}

Quase dois terços das emissões globais de $\mathrm{CO}_{2}$ estão relacionados direta ou indiretamente ao consumo das famílias (Hertwich, 2001). Nos países ricos, os gastos com habitação, sobretudo para o aquecimento das casas, transporte e alimentação constituem as principais fontes de emissão de GEE, e as emissões diretas dos domicílios são quase tão importantes quanto as indiretas geradas na cadeia produtiva. No Brasil, a mudança no uso do solo da terra e florestas deixou de ser a principal origem de GEE. O processo de desenvolvimento econômico associado ao controle do desmatamento aumentou a importância do consumo das famílias como fonte de pressão ambiental. Evitar que este processo ocorra à custa da sustentabilidade é um desafio de largas proporções.

Este artigo procurou identificar os efeitos do aumento do consumo sobre a pressão ambiental através da decomposição estrutural das emissões, por setor produtivo, entre os anos de 1995 e 2009. Vários aperfeiçoamentos da metodologia e novos exercícios são necessários para que os resultados possam ser afirmados de modo categórico. Por exemplo, como o vetor de consumo é tomado em termos monetários, não houve como separar o efeito do aumento de preços sobre o nível de consumo de cada classe. Todo 
acréscimo no consumo por faixa de renda é tomado como um acréscimo na quantidade, quando seria razoável que as classes de renda mais alta consumissem produtos com preços mais elevados, em quantidades nem tão maiores.

O modelo estimado também não leva em conta os produtos importados para o cálculo da pressão ambiental domiciliar, e tampouco os vazamentos sobre a renda dos setores institucionais. As emissões de GEE foram tomadas como proxy para a pressão ambiental. Esta simplificação aproxima a discussão ao problema iminente do aquecimento global, entretanto, deixa escapar uma série de outros impactos ambientais extremamente relevantes, como a perda da biodiversidade, a acidificação dos oceanos, a erosão e perda de solos (Diamond, 2009).

Embora limitado, o exercício chama atenção para alguns fatos importantes. Em primeiro lugar, indica que,embora o controle do desmatamento seja fundamental para a redução das emissões de $\mathrm{CO}_{2}$, a pressão ambiental exclusive os efeitos da MUTF continua subindo com o aumento da produção e consumo. O crescimento dessas emissões é menos errático, mais significativo, e agravado pela concentração das exportações em setores mais intensivos. Em segundo lugar, o efeito composição diminuiu as emissões relacionadas ao consumo, quase exclusivamente devido à queda das emissões relacionadas à agropecuária e outros produtos alimentares, vide a diminuição do peso relativo dos alimentos nos gastos das famílias. Porém, o efeito foi, em muito, ultrapassado pelo efeito escala relacionado ao vetor de consumo. Este mesmo resultado já foi observado em países como a China entre 1992 e 2002 (Peters et al., 2007), a Coréia do Sul entre 1985 e 1995 (Kim, 2008) ou a Inglaterra, entre 1968 e 2000 (Jackson e Papathanasopolou, 2008). O Brasil repete o padrão observado internacionalmente, e que aponta para a inexistência do descolamento crescimento econômico, conforme sugeria a CKA.

\section{REFERÊNCIAS}

BAIOCCHI, G.; MINX, J.; HUBACEK, K. The impact of social factors and consumer behavior on carbon dioxide emissions in the United Kingdom: a regression based on input-output and geodemographic consumer segmentation Data. Journal of Industrial Ecology, n. 1, v. 14, p. 50-72, 2010.

BARROS, L. C. M. Um novo futuro. Novos Estudos, CEBRAP, n. 81, jul. 2008.

BAUMOL, W. J. Macroeconomics of unbalanced growth: the anatomy of urban crisis. The American Economic Review, v. 57, n. 3, p. 415-426, Jun. 1967.

BERTASSO, B. F.; SILVEIRA, F. G.; MAGALHÃES, L. C. G. “Tipologia socioeconômica das famílias das grandes regiões urbanas brasileiras e seu perfil de gastos”. In: SILVEIRA, F. G.; SERVO, L. M. S.; MENEZES, T.; PIOLA, S. F. (Orgs.) Gasto e consumo das famílias brasileiras contemporâneas. Vol. 1. Brasília: IPEA, 2007. 
BERTASSO, B. F. “Aquisição e despesas com bens duráveis, segundo as POF’s de 1995-1996 e 2002-2003”. In: SILVEIRA, F. G.; SERVO, L. M. S.; MENEZES, T.; PIOLA, S. F. (Orgs.) Gasto e consumo das famílias brasileiras contemporâneas. Vol. 1. Brasília: IPEA, 2007.

BOSON, P. H. G. “Transporte rodoviário e mudança do clima no Brasil”. In SEROA DA MOTA, R.; HARGRAVE, J.; LUEDEMANN, G.; GUTIERREZ, M. B. S. (Eds.) Mudança do clima no Brasil: aspectos econômicos, sociais e regulatórios. Brasília: IPEA, 2011.

CARVALHO, A. A.; ALVES, J. E. D. Explorando o consumo das famílias brasileiras e interface com o ciclo de vida e gênero. Oikos: Revista Brasileira de Economia Doméstica, Viçosa, v. 23, n. 1, p. 6-29, 2012.

COHEN, C. A. M. J. Padrões de consumo: desenvolvimento, meio ambiente e energia no Brasil. Tese de Doutorado, Instituto Alberto Luiz Coimbra de Pós-Graduação e Pesquisa de Engenharia, Universidade Federal do Rio de Janeiro, Rio de Janeiro, 2002.

CONFEDERAÇÃO NACIONAL DO TRANSPORTE (CNT). Inventário Nacional de Emissões Atmosféricas por Veículos Automotores Rodoviários. Relatório Final. Brasília: CNT, jan. 2014.

DEDECCA, C. S.; TROVÃO, C. J. B. M.; SOUZA, L. F. Desenvolvimento e equidade. Desafios do crescimento brasileiro. Novos Estudos, CEBRAP, n. 98, mar. 2014.

DIAMOND, J. Colapso: como as sociedades escolhem o fracasso ou o sucesso. Rio de Janeiro: Editora Record, 2009.

DINDA, S. Environmental Kuznets Curve Hypothesis: A survey. Ecological Economics, n. 49, 2004, p. 431-455.

DRUCKMAN, A.; JACKSON, T. The carbono footprint of UK households 1990-2004: a socio-economic disaggregated, quasi-multi-regional input-output model. Ecological Economics, n. 68, 2009, p. 2066-2077.

EMPRESA DE PESQUISA ENERGÉTICA (EPE). Plano Decenal de Expansão de Energia 2020. Brasília: Ministério das Minas e Energia, 2011.

FREITAS, L. C.; KANEKO, S. Decomposing the decoupling of $\mathrm{CO}_{2}$ emissions and economic growth in Brazil. Ecological Economics, v. 70, p. 1459-1469, 2011.

GOUVELLO, C. (Coord.). Estudo de baixo carbono para o Brasil. Brasília: Banco Mundial, 2010.

GUILHOTO, J. J. M.; SESSO FILHO, U. Estimação da matriz insumo-produto a partir de dados preliminares das contas nacionais. Economia Aplicada, v. 9, n. 2, p. 277-299, abr./jun. 2005.

HENRIQUES, S. T.; KANDER, A.The modest environmental relief resulting from the transition to a service economy. Ecological Economics, n. 70, p. 271-282, 2010.

HERTWICH, E, The life cycle environmental impacts of consumption. Economic Systems Research, v. 23, n. 1, p. 27-47, mar. 2001.

INSTITUTO AÇO BRASIL (IAB). Anuário Estatístico 2011. Rio de Janeiro: IAB, 2011.

INSTITUTO BRASILEIRO DE GEOGRAFIA E ESTATÍSTICA (IBGE). Lista de produtos da indústria 2006. Rio de Janeiro: IBGE, 2007.

INSTITUTO BRASILEIRO DE GEOGRAFIA E ESTATÍSTICA (IBGE). Pesquisa Nacional por Amostra de Domicílios - PNAD, 2011. Rio de Janeiro: IBGE, 2012. 
INSTITUTO BRASILEIRO DE GEOGRAFIA E ESTATÍSTICA (IBGE). Pesquisa Nacional por Amostra de Domicílios - PNAD, 2009. Rio de Janeiro: IBGE, 2010.

INSTITUTO BRASILEIRO DE GEOGRAFIA E ESTATÍSTICA (IBGE). Pesquisa de Orçamentos Familiares - POF, 1987, 1995, 2002, 2009. Banco de dados SIDRA. Rio de Janeiro: IBGE, 2013.

JACKSON, T. Prosperity without growth: Economics for a finite planet. London, New York: Earth Scan, 2009.

JACKSON, T.; PAPATHANASOPOLOU, E. Luxury or 'lock-in'? An exploration of unsustainable consumption in the UK: 1968 to 2000. Ecological Economics, v. 68, p. 80-95, 2008.

KAGEYAMA, A.; HOFFMANN, R. Pobreza no Brasil: uma perspectiva multidimensional. Economia e Sociedade, Campinas, v. 15, n. 1 (26), p. 79-112, jan./jun. 2006,

KANDER, A. Baumol's disease and dematerialization of the economy. Ecological Economics, v. 55, p. 119-130, 2005.

KERKHOF, A. C.; NONHEBEL, S.; MOLL, H. C. Relating the environmental impact of consumption to household expenditures: an input-output analysis. Ecological Economics, n. 68, p. 1160-1170, 2009.

KIM, J. Changes in consumption patterns and environmental degradation in Korea. Structural Changes and Economic Dynamics, n. 13, p. 4-48, 2008.

KUZNETS, S. Economic growth and income inequality. The American Economic Review, v. 45, n. 1, mar. 1955.

LORENTZ, A.; SAVONA, M. Evolutionary micro-dynamics and changes in the economic structure. Journal of Evolutionary Economics, v. 18, p. 389-412, 2008.

LUSTOSA, M. C. J. Abertura comercial e padrão de especialização ambiental da indústria brasileira. In: Congresso Brasileiro de Economistas, 14, Recife, 2001.

MACHADO, G.; SHAEFFER, R.; WORREL, E. Energy and carbon embodied in the international trade of Brazil: an IO approach. Ecological Economics, v. 39, 2001.

MEADOWS, D.; RANDERS, J.; BEHRENS, W. Limites do crescimento: um relatório para o projeto do Clubede Roma sobre o dilema da humanidade. SãoPaulo: Perspectiva, 1972.

MINISTÉRIO DA CIÊNCIA, TECNOLOGIA E INOVAÇÃO (MCTI). Estimativas anuais das emissões de gases de efeito estufa no Brasil. Brasília: MCTI, 2013.

MINISTÉRIO DA CIÊNCIA, TECNOLOGIA E INOVAÇÃO. Inventário Brasileiro de Emissões Antrópicas por Fontes e Remoções por Sumidouros de Gases de Efeito Estufa não Controlados pelo Protocolo de Montreal - Parte II da Segunda Comunicação Nacional do Brasil. Brasília: MCTI, 2010.

MINISTÉRIO DO MEIO AMBIENTE (MMA). $1^{\circ}$ Inventário Nacional de Emissões Atmosféricas por Veículos Automotores Rodoviários. Brasília: MMA, 2011.

MONTOYA, M. A.; LOPES, R. L.; GUILHOTO, J. J. M. Desagregação setorial do balanço energético nacional a partir dos dados da matriz de insumo-produto: uma avaliação metodológica. Texto para Discussão, Nereus, n. 05-2013, 2013.

MUNSKGAARD, J.; WIER, M.; LENZEN, M.; DEY, C. Using input-output analysis to measure the environmental pressure of consumption at different spatial levels. Journal of Industrial Ecology, v. 9, n. 1-2, 2005. 
NERI, M. A nova classe média: o lado brilhante da base da pirâmide. São Paulo: Editora Saraiva, 2012.

PETERS, G. P.; WEBER, C. L.; GUAN, D.; HUBACEK, K. China's growing CO2 emissions - a race between increasing consumption and efficiency gains. Environmental Science and Technology, v. 41, n. 17, p. 5939-5944, 2007.

ROCA, J.; SERRANO, M. Income growth and atmospheric pollution in Spain: An input-output approach. Ecological Economics, v. 63, n. 1, p. 230-242, 2007.

ROCKSTRÖM, J.; STEFFEN, W.; NOONE, K.; ET AL. Planetary boundaries: exploring the safe operating space for humanity. Ecology and Society, v. 14, n. 32, 2009.

SEROA DA MOTTA, R. Padrão de consumo, distribuição de renda e meio ambiente no Brasil. Texto para Discussão, IPEA, Rio de Janeiro, n. 856, 2002.

YOUNG, C. E. F.; BARBOSA FILHO, F. H. Comércio internacional, política econômica e poluição no Brasil. In: Encontro Nacional de Economia da ANPEC, 26, Vitória, ES, dez. 1998. 


\section{APÊNDICE}

Tabela A.1 - Valor bruto da produção e coeficientes de emissões, 1995 e 2009

\begin{tabular}{|c|c|c|c|c|}
\hline \multirow{2}{*}{ SETORES } & \multicolumn{2}{|c|}{ Valor da produção $(\mathrm{R} \$ 1,000)$} & \multicolumn{2}{|c|}{ Coeficiente de Emissões } \\
\hline & 1995 & 2009 & 1995 & 2009 \\
\hline Agropecuária & $159.472,75$ & $276.447,00$ & 2,19 & 1,60 \\
\hline Extrativa mineral & $35.624,87$ & $48.083,00$ & 0,18 & 0,22 \\
\hline Extração de petróleo e gás & $25.139,91$ & $82.541,00$ & 0,39 & 0,23 \\
\hline Minerais não metálicos & $38.237,51$ & $52.257,00$ & 0,49 & 0,82 \\
\hline Siderurgia & $65.559,20$ & $70.506,00$ & 0,58 & 0,67 \\
\hline Metalurgia não ferrosos & $18.094,57$ & $26.839,00$ & 0,37 & 0,38 \\
\hline Outros metalúrgicos & $51.747,53$ & $72.245,00$ & 0,00 & 0,00 \\
\hline Máquinas e tratores & $51.402,14$ & $84.648,00$ & 0,01 & 0,00 \\
\hline Material elétrico & $34.332,02$ & $59.498,00$ & 0,02 & 0,01 \\
\hline Equipamentos eletrônicos & $70.183,74$ & $64.812,00$ & 0,01 & 0,00 \\
\hline Automóveis, caminhões e ônibus & $50.366,25$ & $110.582,00$ & 0,00 & 0,00 \\
\hline Outros veículos e peças & $54.136,82$ & $99.426,00$ & 0,00 & 0,01 \\
\hline Madeira e mobiliário & $44.853,22$ & $47.248,00$ & 0,00 & 0,00 \\
\hline Papel e gráfica & $58.290,31$ & $83.724,00$ & 0,06 & 0,05 \\
\hline Indústria da borracha & $12.424,21$ & $17.155,00$ & 0,00 & 0,00 \\
\hline Elementos químicos & $39.875,65$ & $59.894,00$ & 0,11 & 0,08 \\
\hline Refino do petróleo & $133.358,42$ & $198.668,00$ & 0,26 & 0,18 \\
\hline Químicos diversos & $31.542,83$ & $43.880,00$ & 0,04 & 0,04 \\
\hline Farmacêutica e de perfumaria & $44.424,91$ & $66.456,00$ & 0,01 & 0,00 \\
\hline Artigos de plástico & $34.419,52$ & $43.041,00$ & 0,01 & 0,01 \\
\hline Indústria têxtil & $35.070,74$ & $40.363,00$ & 0,04 & 0,03 \\
\hline Artigos do vestuário & $46.969,97$ & $41.550,00$ & 0,00 & 0,00 \\
\hline Fabricação de calçados & $27.934,84$ & $24.239,00$ & 0,00 & 0,00 \\
\hline Indústria do café & $4.986,30$ & $9.380,00$ & 0,02 & 0,02 \\
\hline Beneficiamento de produtos vegetais & $25.713,30$ & $72.209,00$ & 0,02 & 0,01 \\
\hline Abate de animais & $51.273,35$ & $85.056,00$ & 0,01 & 0,01 \\
\hline Indústria de laticínios & $25.715,44$ & $36.726,00$ & 0,01 & 0,01 \\
\hline Indústria de açúcar & $22.070,58$ & $33.378,00$ & 0,03 & 0,02 \\
\hline Fabricação de óleos vegetais & $30.982,30$ & $49.071,00$ & 0,02 & 0,02 \\
\hline Outros produtos alimentares & $75.905,20$ & $84.507,00$ & 0,03 & 0,02 \\
\hline Indústrias diversas & $11.626,87$ & $16.430,00$ & 0,01 & 0,01 \\
\hline Serviços industriais de utilidade pública & $96.783,13$ & $170.669,00$ & 0,09 & 0,09 \\
\hline Construção civil & $182.063,71$ & $285.293,00$ & 0,01 & 0,00 \\
\hline Comércio & $322.992,38$ & $493.217,00$ & 0,00 & 0,00 \\
\hline Transporte & $167.262,86$ & $270.901,00$ & 0,61 & 0,56 \\
\hline Comunicações & $53.230,39$ & $206.566,00$ & 0,00 & 0,00 \\
\hline Instituições financeiras & $160.431,39$ & $310.934,00$ & 0,00 & 0,00 \\
\hline Serviços prestados às famílias & $213.204,80$ & $368.886,00$ & 0,00 & 0,00 \\
\hline Serviços prestados às empresas & $105.586,50$ & $236.383,00$ & 0,00 & 0,00 \\
\hline Aluguel de imóveis & $99.791,42$ & $253.718,00$ & 0,00 & 0,00 \\
\hline Administração pública & $434.783,13$ & $685.810,00$ & 0,00 & 0,00 \\
\hline Serviços privados não-mercantis & $65.737,24$ & $97.505,00$ & 0,00 & 0,00 \\
\hline TOTAL & $3.313 .602,21$ & $5.480 .741,00$ & 0,18 & 0,15 \\
\hline
\end{tabular}

Nota: O coeficiente de emissões é dado em $\mathrm{GgCO}_{2}$ e por $\mathrm{R} \$ 1.000,00$. Fonte: Elaboração própria. 